\title{
Adrenal Function in Sick Very Preterm Infants
}

\author{
MARIANNE W. A. HUYSMAN, ANITA C. S. HOKKEN-KOELEGA, MARIA A. J. DE RIDDER, AND \\ PIETER J. J. SAUER
}

\author{
Department of Pediatrics, Division of Neonatology, Sophia Children's Hospital/University Hospital \\ Rotterdam, 3000 CB Rotterdam, The Netherlands [M.W.A.H.]; Department of Pediatrics, Division of \\ Endocrinology, Sophia Children's Hospital/University Hospital Rotterdam, 3000 CB Rotterdam, The \\ Netherlands [A.C.S.H.K.]; Department of Biostatistics and Epidemiology, Erasmus University, 3000 DR \\ Rotterdam, The Netherlands [M.A.J.D.R.]; and Department of Pediatrics, Beatrix Children's \\ Hospital/University Hospital Groningen, 9700 CB Groningen, The Netherlands [P.J.J.S.]
}

\begin{abstract}
Some very preterm neonates admitted to the neonatal intensive care unit show circulatory and respiratory problems that improve after administration of steroids. It is unclear whether these symptoms could be caused by adrenal insufficiency. The objective of our study was to investigate the cortisol levels and the cortisol release from the adrenals after ACTH in very preterm infants with and without severe illness and to find whether a relation exists between adrenal function and outcome. An ACTH test $(0.5 \mu \mathrm{g})$ was performed on $\mathrm{d} 4$ in 21 very preterm infants (gestational age, 25.6-29.6 wk; birth weight, 485-1265 g). Baseline cortisol and 17-hydroxyprogesterone (17OHP) levels and the cortisol levels 30, 60, and $120 \mathrm{~min}$ after ACTH administration were measured. The Score for Neonatal Acute Physiology was used to measure illness severity. All infants showed an increase in cortisol levels after ACTH, but the cortisol levels were significantly lower in the ventilated more severely ill infants. After adjusting for birth weight and gestational age, the mean baseline cortisol levels and cortisol/17OHP ratios were significantly lower
\end{abstract}

\section{ABSTRACT}

and the 17OHP levels significantly higher in the ventilated infants compared with the nonventilated infants. Patients with an adverse outcome had significantly lower baseline cortisol/ 17OHP ratios and 60-min cortisol levels during ACTH testing ( $p=0.002$ and $p=0.03$, respectively). These data suggest an insufficient adrenal response to stress in sick ventilated very preterm infants with gestational ages younger than $30 \mathrm{wk}$ compared with nonventilated less sick preterm infants. Further studies are required to investigate whether supplementation with physiologic doses of hydrocortisone may benefit the outcome. (Pediatr Res 48: 629-633, 2000)
Abbreviations
17OHP, 17-hydroxyprogesterone
C/17OHP, cortisol/17-hydroxyprogesterone ratio
CYP11B, 11-hydroxylase
CYP21A2, 21-hydroxylase
SNAP, Score for Neonatal Acute Physiology

With increasing neonatal and obstetric treatment modalities, younger and smaller neonates are admitted to neonatal intensive care units (NICU). Some of these infants show not only respiratory but also circulatory problems such as systemic hypotension resistant to volume expansion and cardiotonic drugs but reactive to the administration of corticosteroids (1). Declining cortisol levels in the first week of life in patients with ongoing respiratory problems are reported (2), and a higher incidence of bronchopulmonary dysplasia (BPD) in patients with an insufficient cortisol response to ACTH has been found (3).

In the $1970 \mathrm{~s}$, the adrenal function of preterm neonates was investigated after administration of a short course of corticosteroids during gestation, and no signs of adrenal insufficiency

Received August 4, 1999; accepted May 23, 2000.

Correspondence: Marianne W. A. Huysman, M.D., Department of Pediatrics, Division of Neonatology, Sophia Children's Hospital/University Hospital Rotterdam, P.O. Box 2060, 3000 CB Rotterdam, The Netherlands. were found (4). These preterm neonates, however, were born after a greater gestational age, had a higher birth weight than the infants presently seen in the NICU, and were tested with a relatively high dose of ACTH $(15 \mu \mathrm{g} / \mathrm{kg})$ on the first day of life. In infants exposed to long courses of corticosteroids during gestation, no evidence of adrenal insufficiency was found when tested with a higher dose of ACTH $(36 \mu \mathrm{g} / \mathrm{kg})(5)$. These infants, however, were of greater gestational age compared with the very preterm infants now treated at the NICU.

Insufficient cortisol production may not only lead to disturbed vital signs such as low blood pressure and poor glycemic control but also may influence illness severity and outcome.

According to previous studies, cortisol and 17OHP levels are high on the first day of life. Thereafter, cortisol levels decrease immediately and tend to increase at $\mathrm{d} 4$ and 5 , whereas 17OHP levels decline immediately after birth but remain stable from d 2 until 7 (6-9). Recent studies show low 
cortisol levels in ill very preterm infants $(10-13)$, whereas others find low cortisol levels that may be explained as physiologic as these infants no longer required mechanical ventilation (14). Cortisone levels decline immediately in the first $2 \mathrm{~h}$ and very gradually thereafter in the first week of life. The levels between term and preterm infants are not significantly different. Corticosterone levels are much lower than cortisol levels, increase in the first $2 \mathrm{~h}$, decrease until $6 \mathrm{~h}$, and decrease again to $24 \mathrm{~h}$, after which a slight increase is seen.

The aim of the present study was to investigate the release of cortisol and the precursor 17OHP from the adrenals of very preterm infants under conditions of stress compared with the nonstressed situation and to evaluate whether a relation exists between the cortisol release on $\mathrm{d} 4$ of life and the development of BPD, severe cerebral complications, and mortality.

\section{METHODS}

\section{Patients}

Twenty-one patients admitted to the NICU of the Sophia Children's Hospital were included in the present study. The inclusion criteria were immediate admission at the intensive care unit after birth, gestational age younger than $30 \mathrm{wk}$, and indwelling arterial line. Exclusion criteria were a maternal history of endocrine disorders such as diabetes, thyroid or adrenal problems, or congenital malformations. The present study was approved by the local Medical Ethics Committee, and informed consent was obtained from the parents of each child.

Infants were studied on $\mathrm{d} 4$ of life. Most of the infants were tested at $0800 \mathrm{~h}$, but some were tested in the afternoon. A standard dose of $0.5 \mu \mathrm{g}$ of ACTH was given. ACTH was diluted with saline to a concentration of $1 \mu \mathrm{g} / \mathrm{mL}$ in a plastic syringe and immediately given i.v. by a short venous cannula and a connection close to the patient.

Baseline blood samples for cortisol, 17OHP, and C/17OHP were taken. Cortisol was also measured 30,60, and $120 \mathrm{~min}$ after administration of ACTH. All blood samples were taken from an indwelling arterial line. Oxygen saturation was measured continuously by pulse oxymetry (Nellcor 3000), ventilation settings were recorded every $30 \mathrm{~min}$ during testing, and arterial blood pressure was measured continuously.

Illness severity was measured by the SNAP score (15). We performed this score on $\mathrm{d} 4$ to determine whether other pathophysiologic parameters such as blood pressure, frequency of bradycardia, disturbances in glucose, in serum electrolytes, and liver or kidney function, often seen in more severely ill patients and not always accompanied by higher ventilation settings, were related to the adrenal function. Although the SNAP score is designed to reflect the severity of illness on $\mathrm{d} 1$, we believe that the score on $\mathrm{d} 4$ also reflects the severity of illness on $\mathrm{d} 4$. BPD was defined as persisting respiratory problems with a need for oxygen at d 28 and an abnormal chest x-ray (16). Adverse outcome was defined as mortality or severe morbidity defined by severe cerebral problems (intracranial hemorrhage grade 3 or more and severe cystic leukomalacia) and/or BPD.

\section{Hormone Assays}

Serum cortisol was determined by using a commercial chemiluminescent labeled antibody assay (Nichols Institute Diagnostics Cortisol Kit, San Juan Capistrano, CA, U.S.A.). The intraassay coefficients of variation were $3.1-4.8 \%$, and the interassay coefficients of variation were $6.2-10.2 \%$. Crossreactivity with cortisone is unknown within physiologic ranges. Hyperbilirubinemia did not influence the assay.

The precursor 17OHP was determined by RIA (Coat-ACount, Diagnostic Products Corp., Los Angeles, CA, U.S.A.) (Laboratory Internal Medicine, Academic Hospital Rotterdam, The Netherlands; Head, Prof. Dr. F. de Jong). The interassay coefficient of variation was $10 \%$ for $17 \mathrm{OHP}$. The main crossreactivity in the 17OHP assay occurred with progesterone $5 \%$ (17).

\section{Statistical Analyses}

Statistical analyses were made by SPSS package, version 8.0 for Windows, released in 1997. Results are expressed as mean (SD) unless indicated otherwise.

Linear regression analysis was used to examine the relations between determinants such as birth weight, gestational age, birth weight SD score (SDS), illness severity, and ventilation and continuous outcome variables such as cortisol, 17OHP, and $\mathrm{C} / 17 \mathrm{OHP}$. The relation with ventilation, BPD, and adverse outcome was adjusted for gestational age and birth weight.

The baseline 17OHP data showed a skewed distribution and were $\log$ transformed for statistical analyses.

$$
\text { A } p \text { value }<0.05 \text { was considered significant. }
$$

\section{RESULTS}

Twenty-one patients were enrolled in the study (14 male, seven female); the patients had a mean gestational age of 27.7 wk [interquartile (i.q.) range, 26.4-28.9 wk], a mean birth weight of $887 \mathrm{~g}$ (i.q. range, $708-1005 \mathrm{~g}$ ), a mean SDS for birth weight of -1.43 (i.q. range, -2.82 to -0.30 ), and a mean weight at day of testing of $845 \mathrm{~g}$ (i.q. range, 738-933 g). Sixteen patients received antenatal betamethasone, and 10 patients were artificially ventilated during ACTH testing. The ventilated and nonventilated group were not significantly different except for gestational age, birth weight, and SNAP score ( $p=0.03, p=0.03$, and $p=0.003$, respectively). The ACTH dose expressed in $\mu \mathrm{g} / \mathrm{kg}$ was not significantly different between the groups. Five patients died in the neonatal period.

\section{Baseline Cortisol Levels}

The mean (SD) baseline cortisol level for the total group was 277 (144) nmol/L. The baseline cortisol levels were not influenced by the mode of delivery or the presence of preeclampsia in the mother and did not correlate with gestational age, birth weight, and birth weight SDS.

In boys, the mean baseline cortisol level was $116 \mathrm{nmol} / \mathrm{L}$ lower than in girls $(p=0.21)$. In the patients treated with antenatal steroids, the mean baseline cortisol level was not significantly lower compared with the group without use of antenatal steroids. 


\section{Cortisol Response after ACTH}

The mean (SD) cortisol levels 30 and 60 min after ACTH administration were $558(180)$ and $753(250) \mathrm{nmol} / \mathrm{L}$, respectively. Some infants continued to have high cortisol levels at $120 \mathrm{~min}$, but others already showed a decline. The mean (SD) cortisol level at $120 \mathrm{~min}$ was $694(251) \mathrm{nmol} / \mathrm{L}$.

The cortisol levels at 30 and $60 \mathrm{~min}$ were positively correlated with gestational age $(r=0.57, p=0.008$ and $r=0.59$, $p=0.006$, respectively). The 60 -min cortisol levels showed a positive correlation with birth weight $(r=0.49, p=0.029)$. The cortisol levels at 30 and 60 min were not correlated with the ACTH dose per kilogram of body weight $(r=-0.26, p=$ 0.26 and $r=-0.43, p=0.06$, respectively) or with birth weight SDS $(r=-0.23, p=0.92$ and $r=0.82, p=0.73)$.

\section{Baseline 170HP Levels}

The baseline levels of 17OHP showed a skewed distribution and were $\log$ transformed for statistical analyses. The baseline 17OHP levels showed a negative correlation with gestational age $(r=-0.53, p=0.020)$ but did not correlate with birth weight or birth weight SDS. The baseline 17OHP levels were not related with the baseline cortisol levels but were negatively correlated with the cortisol levels at 30 and $60 \min (r=-0.52$, $p=0.025$ and $r=-0.51, p=0.032$, respectively).

\section{Cortisol and 17OHP Levels in Relation to Ventilation}

The mean baseline cortisol level was not significantly lower, but the cortisol levels at 30 and $60 \mathrm{~min}$ after administration of ACTH were significantly lower in the ventilated infants compared with the nonventilated infants $(p<0.001$ and $p<0.01$, respectively) (Fig. 1). The mean baseline 17OHP level in the ventilated infants was $45.6(34.3) \mathrm{nmol} / \mathrm{L}$ and significantly higher compared with the nonventilated infants 8.5 (6.4) $\mathrm{nmol} / \mathrm{L}(p=0.014)$. The mean baseline $\mathrm{C} / 17 \mathrm{OHP}$ was signif-

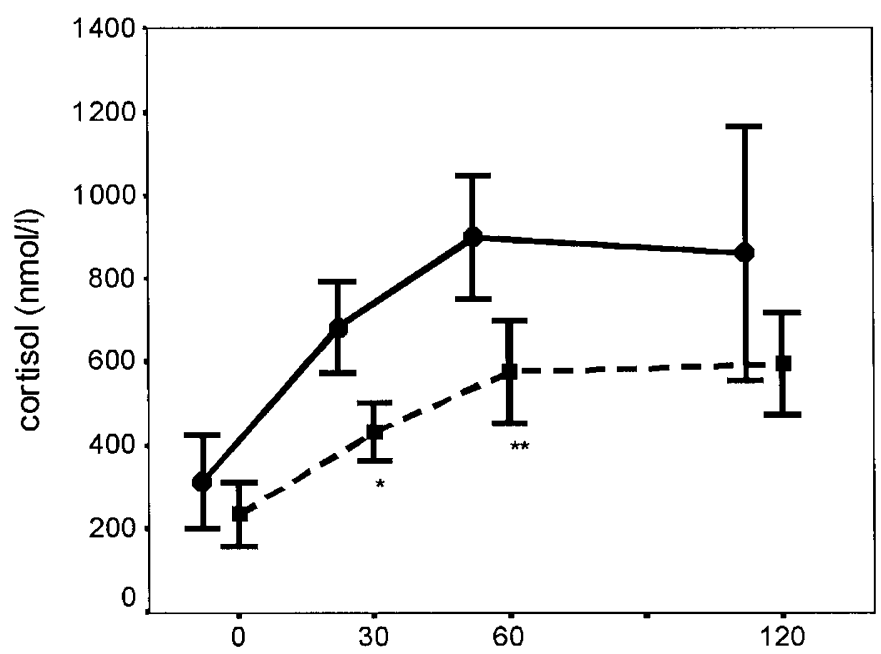

time after $\mathrm{ACTH}$ (minutes)

Figure 1. Cortisol levels before and after ACTH $(0.5 \mu \mathrm{g})$ in ventilated and nonventilated infants. Results are expressed as mean cortisol levels with $95 \%$ confidence intervals. $\boldsymbol{\bullet}=$ nonventilated infants, $\mathbf{\square}=$ ventilated infants. $\star p<$ $0.001 v s$ nonventilated group, $\star \star p<0.01 v s$ nonventilated group. icantly lower in the ventilated compared with the nonventilated infants $(p=0.004)$. After adjusting for gestational age and birth weight, the mean baseline cortisol, the cortisol level at 30 $\mathrm{min}$, and the $\mathrm{C} / 17 \mathrm{OHP}$ were significantly lower in the ventilated group ( $p=0.046, p=0.013$, and $p=0.015$, respectively).

\section{Cortisol and 170HP Levels in Relation to Illness Severity}

The baseline cortisol levels were not related to SNAP scores, but the 30- and 60-min cortisol levels were negatively correlated with higher SNAP scores, indicating lower cortisol levels at higher SNAP scores $(r=-0.62, p=0.005$ and $r=-0.61$, $p=0.006$, respectively) (Fig. $2, A-C$ ). For every increment of 10 points in the SNAP score, the 30-min cortisol level decreased with $215 \mathrm{nmol} / \mathrm{L}$ and the $60-\mathrm{min}$ cortisol level decreased with $272 \mathrm{nmol} / \mathrm{L}$.

The baseline 17OHP level was positively correlated with higher illness severity as measured by SNAP $(r=0.49, p=$ $0.039)$.

\section{Cortisol and 170HP Levels in Relation to Outcome}

BPD. Patients who developed BPD were not significantly different with respect to gestational age, birth weight, and birth weight SDS compared with patients who did not develop BPD.

Patients who developed BPD showed a significantly lower mean cortisol level at $60 \mathrm{~min}(p=0.029)$ than patients who did not develop BPD. In addition, the mean baseline value for $17 \mathrm{OHP}$ was significantly higher and mean $\mathrm{C} / 17 \mathrm{OHP}$ was significantly lower in infants who developed BPD $(p=0.009$ and $p=0.008$, respectively).

Adverse outcome. Gestational age, birth weight, and birth weight SDS were not significantly different in patients with a poor outcome compared with patients with a good outcome.

Patients with a poor outcome showed a significantly lower mean 60-min cortisol level $(p=0.025)$, a significantly higher mean baseline 17OHP level $(p=0.006)$, and a significantly lower mean baseline C/17OHP $(p=0.002)$ compared with infants with a better outcome.

\section{DISCUSSION}

We performed this study to evaluate the capacity of the adrenals of very preterm infants in the first week of life to produce cortisol under normal conditions and under conditions of stress.

Our study suggests that sick very preterm infants do not release more cortisol than less severely ill very preterm infants. Our data show significantly lower baseline cortisol levels and a diminished cortisol response after ACTH in ventilated compared with nonventilated infants and a significantly lower $\mathrm{C} / 17 \mathrm{OHP}$ in ventilated infants. A normal reaction to stress would show a higher cortisol level with increasing illness as is seen in critically ill adults (18). Our study, however, was not designed to answer whether these infants became ill because of a low cortisol production or showed adrenal insufficiency as a result of their severe illness. The results, however, do support the idea of considering supplementation of cortisol in severely 

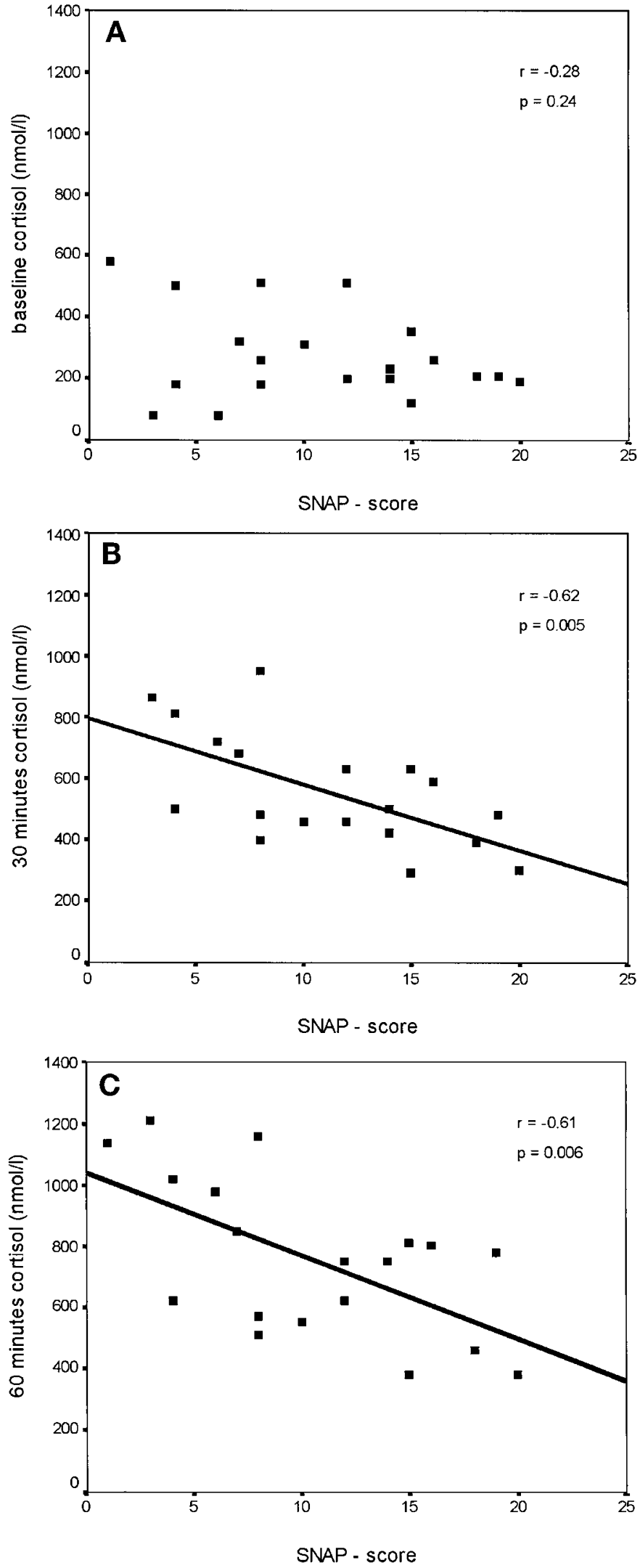

Figure 2. $(A)$ Baseline cortisol levels in relation to illness severity (SNAP score). (B) Thirty-minute cortisol levels after ACTH administration in relation to illness severity; regression line: $\mathrm{C} 30=797-22$ SNAP. (C) Sixty-minute cortisol levels after ACTH administration in relation to illness severity; regression line: $\mathrm{C} 60=1041-27$ SNAP. ill very preterm infants with ongoing blood pressure problems and persisting hypoglycemia.

Scott and Watterberg (19) have demonstrated that very sick infants with gestational ages younger than 28 wk have lower morning cortisol levels than less severely ill infants of the same gestational age. This negative correlation between illness and morning cortisol levels, however, seems diminished in patients of greater gestational age. Other markers of illness such as ventilatory support pattern or use of surfactant were also negatively correlated with cortisol levels.

Our findings are in contrast with Hingre et al. (11) who found in sick preterm and healthy full-term infants (20) comparable baseline cortisol levels and with Thomas et al. (21) who even showed higher baseline cortisol levels in sick compared with healthy preterm infants. The difference with our data may be due to the fact that the patients in the Thomas study had a gestational age greater than $30 \mathrm{wk}$, whereas our patients were all younger than $30 \mathrm{wk}$.

In agreement with Lee et al. (10) and in contrast with other studies $(19,22)$, we did not find a relation between baseline cortisol level and gestational age. It could be that our population was too homogeneous in gestational age to detect a relationship.

Although we are not informed about the amount of crossreactivity between baseline cortisol and cortisone, we know from other studies that the levels of cortisone can be in the same range as the cortisol levels $(8,23,24)$. This may have contributed to the measured baseline cortisol levels, especially when the baseline cortisol levels are low. We did find a difference in baseline cortisol levels between ventilated and nonventilated infants. As it is unlikely the levels of cortisone were higher in ventilated compared with nonventilated infants, the conclusion remains true.

The interpretation of ACTH test results is complicated by the fact that no agreement exists about the correct dose of $\mathrm{ACTH}$, and different criteria for diagnosing adrenal insufficiency are used in the literature. We tested with a fixed dose of $0.5 \mu \mathrm{g}$, corresponding with an ACTH dose of $0.5-1 \mu \mathrm{g} / \mathrm{kg}$ or $10-15 \mu \mathrm{g} / 1.73 \mathrm{~m}^{2}$ and found differences between ventilated and nonventilated infants.

The baseline cortisol levels in ventilated infants are remarkably low considering the degree of illness. Ventilated infants do have significantly lower 30- and 60-min cortisol levels after ACTH compared with nonventilated infants, which can only be caused by a lower adrenal cortisol release in response to ACTH administration. It is known from the literature that increases in cortisol are much higher than increases in cortisone after ACTH $(23,25)$. It is only when the increase in cortisol after $\mathrm{ACTH}$ is very low that cortisone can still contribute to the measured cortisol level. In fact, we may have underestimated the differences in cortisol response between ventilated and nonventilated infants.

Thus, in contrast with earlier studies $(4,26,27)$, we found evidence for adrenal insufficiency in very preterm ventilated infants when tested with a low-dose ACTH. It seems that the adrenals in these ventilated sick infants are less capable of releasing cortisol after an additional ACTH stimulus compared with nonventilated infants. Possible explanations may be that 
the adrenals in these infants were already down-regulated by high circulating interleukin levels and no longer reactive to high serum ACTH levels or that the adrenals in the ventilated infants were not capable enough of recognizing higher serum ACTH levels. The ventilated infants, however, showed higher levels of the cortisol precursor 17OHP and a lower C/17OHP compared with nonventilated infants. This indicates that the adrenals are responsive to ACTH and produce precursors but, at the same time, may not be able to convert the precursor to cortisol. Hanna et al. (27) reported a normal ACTH and cortisol response to ovine corticotropin releasing hormone $(\mathrm{CRH})$ and a normal cortisol response to exogenous ACTH in extremely low birth weight infants, thereby suggesting that the low baseline cortisol levels were partly due to an inability of the brain to recognize the stress of illness or an inability of the hypothalamus to secrete CRH. They, however, used a high dose of ACTH $(62.5 \mu \mathrm{g})$ and $1 \mathrm{~d}$ after CRH testing, which by itself induces an increase in baseline cortisol levels. $\mathrm{Ng}$ et al. (28) showed a higher ACTH response after CRH administration in ventilated infants without an increase in cortisol levels, suggesting that the pituitary is more matured than the adrenals in preterm infants.

Our study showed significantly higher 17OHP levels and lower $\mathrm{C} / 17 \mathrm{OHP}$ in ventilated infants compared with nonventilated infants adjusted for gestational age and birth weight as well as in more severely ill infants. Both suggest a reaction of the adrenals to stress by increasing a cortisol precursor but showing a lower capacity, especially in the severe ill and ventilated infants, to convert this precursor $17 \mathrm{OHP}$ to cortisol. The high levels of 17OHP in relation to cortisol can be caused by a decreased activity of the enzyme CYP21A2 or due to a lower conversion of 11-deoxycortisol to cortisol by CYP11B, which seems to be a greater problem in the sick very preterm infant. Higher 17OHP levels in sick preterm infants compared with term infants have been described earlier $(10,29,30)$. High baseline levels of 17OH-pregnenolone, 170HP, and 11desoxycortisol in sick infants with gestational ages younger than 30 wk compared with term infants have been reported and are also consistent with a decreased CYP11B activity (11).

In summary, our data demonstrate lower baseline cortisol levels, a lower cortisol response to ACTH, higher 17OHP levels, and lower $\mathrm{C} / 17 \mathrm{OHP}$ in ventilated very preterm infants compared with nonventilated preterm infants and those who did not have an adverse outcome. The data suggest an insufficient adrenal response to stress in sick ventilated very preterm infants with gestational ages younger than 30 wk. Further studies are required to investigate whether supplementation with physiologic doses of hydrocortisone may benefit the outcome.

\section{REFERENCES}

1. Helbock HJ, Insoft RM, Conte FA 1993 Glucocorticoid-responsive hypotension in extremely low birth weight newborns. Pediatrics 92:715-717
2. Scott SM, Watterberg KL, Backstrom CS, Werner SB, Wells LR 1992 Cortisol concentrations in the ill very low birth weight infant. Pediatr Res 31:222

3. Watterberg KL, Scott SM 1995 Evidence of early adrenal insufficiency in babies who develop bronchopulmonary dysplasia. Pediatrics 95:120-125

4. Ohrlander S, Gennser G, Nilsson KO, Eneroth P 1977 ACTH test to neonates after administration of corticosteroids during gestation. Obstet Gynecol 49:691-694

5. Arad I, Landau H 1984 Adrenocortical reserve of neonates born of long-term, steroid-treated mothers. Eur J Pediatr 142:279-280

6. Kojima S, Yanaihara T, Nakayama T 1981 Serum steroid levels in children at birth and in early neonatal period. Am J Obstet Gynecol 140:961-965

7. Sippell WG, Becker H, Versmold HT, Bidlingmaier F, Knorr D 1978 Longitudinal studies of plasma aldosterone, corticosterone, deoxycorticosterone, progesterone, 17-hydroxyprogesterone, cortisol, and cortisone determined simultaneously in mother and child at birth and during the early neonatal period. I. Spontaneous delivery. J Clin Endocrinol Metab 46:971-985

8. Doerr HG, Sippell WG, Versmold HT, Bidlingmaier F, Knorr D 1988 Plasma mineralocorticoids, glucocorticoids, and progestins in premature infants: longitudinal study during the first week of life. Pediatr Res 23:525-529

9. Doerr HG, Versmold HT, Bidlingmaier F, Sippell WG 1989 Adrenocortical steroids in small for gestational age term infants during the early neonatal period. Pediatr Res 25:115-118

10. Lee MM, Rajagopalan L, Berg GJ, Moshang Jr T 1989 Serum adrenal steroid concentrations in premature infants. J Clin Endocrinol Metab 69:1133-1136

11. Hingre RV, Gross SJ, Hingre KS, Mayes DM, Richman RA 1994 Adrenal steroidogenesis in very low birth weight preterm infants. J Clin Endocrinol Metab 78:266270

12. Hanna CE, Jett PL, Laird MR, Mandel SH, LaFranchi SH, Reynolds JW 1997 Corticosteroid binding globulin, total serum cortisol, and stress in extremely lowbirth-weight infants. Am J Perinatol 14:201-204

13. Jett PL, Samuels MH, McDaniel PA, Benda GI, LaFranchi SH, Reynolds JW, Hanna CE 1997 Variability of plasma cortisol levels in extremely low birth weight infants. J Clin Endocrinol Metab 82:2921-2925

14. Merz U, Pfäffle R, Peschgens T, Hörnchen H 1998 The hypothalamic-pituitaryadrenal axis in preterm infants weighing $<$ or $=1250 \mathrm{~g}$ : association with perinatal data and chronic lung disease. Acta Paediatr 87:313-317

15. Richardson DK, Gray JE, McCormick MC, Workman K, Goldmann DA 1993 Score for neonatal acute physiology: a physiologic severity index for neonatal intensive care. Pediatrics 91:617-623

16. Northway WH, Rosan RC, Porter DY 1967 Pulmonary disease following respiratory therapy of hyaline membrane disease: bronchopulmonary dysplasia. N Engl J Med 276:357-368

17. De Jong FH, Mallios C, Jansen C, Scheck PAE, Lamberts SWJ 1984 Etomidate suppresses adrenocortical function by inhibition of $11 \beta$-hydroxylation. J Clin Endocrinol Metab 59:1143-1147

18. Frayn KN 1986 Review. Hormonal control of metabolism in trauma and sepsis. Clin Endocrinol 24:577-599

19. Scott SM, Watterberg KL 1995 Effect of gestational age, postnatal age, and illness on plasma cortisol concentrations in premature infants. Pediatr Res 37:112-116

20. Wiener D, Smith J, Dahlem S, Berg G, Moshang Jr T 1987 Serum adrenal steroid levels in healthy full-term 3-day-old infants. J Pediatr 110:122-124

21. Thomas S, Murphy JF, Dyas J, Ryalls M, Hughes IA 1986 Response to ACTH in the newborn. Arch Dis Child 61:57-60

22. Wittekind CA, Arnold JD, Leslie GI, Lutrell B, Jones MP 1993 Longitudinal study of plasma ACTH and cortisol in very low birth weight infants in the first 8 weeks of life. Early Hum Dev 33:191-200

23. Hillman DA, Giroud CJP 1965 Plasma cortisone and cortisol levels at birth and during the neonatal period. J Clin Endocr 25:243-248

24. Nomura S 1997 Immature adrenal steroidogenesis in preterm infants. Early Hum Dev 49:225-233

25. Morineau G, Boudi A, Barka A, Gourmelen M, Degeilh F, Hardy N, Al-Hanak A, Soliman H, Gosling JP, Julien R, Brerault JL, Boudou P, Aubert P, Villette JM, Pruna A, Galons H, Fiet J 1997 Radioimmunoassay of cortisone in serum, urine, and saliva to assess the status of the cortisol-cortisone shuttle. Clin Chem 43:1397-1407

26. Noguchi A, Reynolds JW 1978 Serum cortisol and dehydroepiandrosterone sulfate responses to adrenocorticotropin stimulation in premature infants. Pediatr Res 12:1057-1061

27. Hanna CE, Keith LD, Colasurdo MA, Buffkin DC, Laird MR, Mandel SH, Cook DM, LaFranchi SH, Reynolds JW 1993 Hypothalamic pituitary adrenal function in the extremely low birth weight infant. J Clin Endocrinol Metab 76:384-387

28. Ng PC, Wong GWK, Lam CWK, Lee CH, Wong MY, Fok TF, Wong W, Chan DCF 1997 Pituitary-adrenal response in preterm very low birth weight infants after treatment with antenatal corticosteroids. J Clin Endocrinol Metab 82:3548-3552

29. Al Saedi S, Dean H, Dent W, Cronin C 1995 Reference ranges for serum cortisol and 17-hydroxyprogesterone levels in preterm infants. J Pediatr 126:985-987

30. Murphy JF, Joyce BG, Dyas J, Hughes IA 1983 Plasma 17-hydroxyprogesterone concentrations in ill newborn infants. Arch Dis Child 58:532-534 